\title{
Branch Standards as the Method of Optimizing of Capital Structure
}

\author{
Milan Hrdý \\ University of Economics in Prague, Czech Republic
}

\begin{abstract}
This article is about the problem of optimizing of the capital structure of the concrete firm and about the possibility to use the passive way of optimizing of this capital structure on the basis of the so-called branch standards. Branch standards are defined as some average indebtedness that the firms are trying to follow. There are a lot of theories available, but the final process of optimizing of the capital structure of the concrete firm is very complicated and it is necessary to cope with a lot of application problems. Besides traditional theory, none of the further theories offer some concrete recommended optimal indebtedness. For that reason, the possibility to optimize the capital structure based on the passive way is represented besides other things by the so-called branch standards. The aim of this article is to judge if it is possible to identify this average indebtedness in different branches and in different countries and continue in the previous researches of the author. The hypothesis was stated that it is possible only in selected branches in selected countries as it was stated also in previous researches of the author. The research is realized in the five selected branches, Pharmacy, Furniture Production, Wood (Forest) Production, Water Supply, and Air Transport in the Czech Republic and in the USA. Data for the years 2008-2016 were obtained from the system Albertina Data at the University of Economics in Prague and from web pages of Prof. Aswath Damodaran in the USA. There were identified so-called branch standards in the Czech Republic for the branch Pharmacy with the indebtedness (45\%), Furniture Production with the indebtedness (54\%), Water Supply with the indebtedness (30-35\%), Wood (Forest) Products with the indebtedness (40\%), and Air Transport with the indebtedness (70-75\%). There are also identified so-called branch standards in the USA for the branches Pharmacy 34\%, Furniture Production $40 \%$ and Water Supply 50\%-55\%.The values were verified by the data for the year 2016 and the so-called branch standards were confirmed excluding the branch Air Transport in the Czech Republic and for the branch Water Supply in the USA. The branches Pharmacy and Furniture Production show small differences.
\end{abstract}

Keywords: capital structure, optimizing, branch standards, analysis

\section{Introduction}

Optimizing of the capital structure of the concrete firm is one of the very important parts of the long-term financial management. This process can positively and negatively influence the basic financial goal which is represented by the maximizing of the market value of the firm. But the process of optimizing is very complicated. Debt in the capital structure represents the positive effect of the interest tax shield, but if there is a

Acknowledgment: Milan Hrdý would like to thank institutional financial support IP 100040 from the University of Economics in Prague, Faculty of Finance and Accounting, Czech Republic.

Milan Hrdý, doc. JUDr., Ing., Ph.D., Faculty of Finance and Accounting, University of Economics in Prague, Prague, Czech Republic. 
lot of debt the financial distress threatens. For that reason, optimizing of the capital structure of the concrete firm is very difficult both in theory and in practice. There are a lot of theories available, but every theory has its application problem. The firm can choose the active and passive way of optimizing. The active way is represented mainly by the traditional theory and the passive way of optimizing by Pecking Order Theory or by the so-called branch standards. Branch standards are defined as the average indebtedness in some concrete branches which firms are trying to follow. Because the active way of optimizing is represented by the calculation of the weighted average cost of capital and this is a very complicated thing mainly in case of the different levels of the indebtedness, the passive way could be suitable for the firm. But can the firm do the optimizing of the capital structure according to the branch standards? Is it possible in real economy to identify the average indebtedness or not? The answer to this question is not easy and for that reason the aim of this article is to judge if it is possible to identify this average indebtedness in different branches and in different countries. This article continues in the previous researches of the author published also in this journal (Hrdý, 2018). These researches show that

It is possible to identify the average indebtedness and so-called Branch standards, but only in the selected branches where the tendency of the average indebtedness is relatively stabilized and where there is a minimum volatility in the last few years. (Hrdý, 2018, pp. 165-173)

\section{Theory and Hypotheses}

There are a few theories about optimizing of the capital structure of the firm. The most important is the traditional theory that is based on the average cost of capital. The average cost of capital is represented by the arithmetical average of the individual cost of capital of the different types of the firm's capital. This theory states that the optimal capital structure is represented by the minimum average cost of capital. It is possible to fall in this point with the maximizing of the market value of the firm in case of the stabilized expected incomes (Valach, 2011). The next theory which is called Compromising Theory is relatively very close to the traditional theory because it works with the influence of the interest tax shield and the cost of financial districts which both cause the $U$ shape of the curve of the weighted average cost of capital, because firstly the weighted average cost of capital is decreasing, and then, it is increasing. In fact, first is the positive influence of the interest tax shield and then the negative influence of the cost of the financial distress. The optimum arrives if the present value of the tax interest shield exceeds maximum the present value of the cost of financial distress.

The next theory is represented by two propositions of Modigliani and Miller (MM). The first states that the market value of the firm is independent on the capital structure and only the structure of the firm's assets is important. According to this approach, the process of the optimizing of the capital structure is not important. MM suppose tax free environment and perfect capital markets. Then, MM admitted the existence of taxes and they recommended to the firm the maximum of debt if the firm is expecting to have profit and can use the tax interest shield. But MM do not consider the existence of the cost of financial distress.

Brealey, Myers, and Allen (2014) represented the next theory that is called the theory about four dimensions of the capital structure and takes into consideration the following four dimensions-taxes, risk, asset type, and financial slack. It is recommended to accept more debt in case the firm is expecting profit and a relatively lesser risk of business and there is a prevalence of tangible assets.

The final theory is called Pecking Order Theory which is not in reality the theory, but the results of the practical researches of firm's behavior. It was found out that more than $70 \%$ of firms mainly in the USA prefer 
internal financial sources, then debt and finally external equity, mainly stocks (Valach, 2011). According to this theory, the final debt share is not actively identified, but it is the result of the process of financing. If for example there are enough internal financial sources, the indebtedness is zero. If for example the firm needs capital 10 million USD and only seven million USD of internal financial sources are available, then it is necessary to obtain three million USD of debt and the final indebtedness is $30 \%$. For that reason, this process is called the passive way of optimizing.

Besides the different theories, the so-called branch standards and determinants of the capital structure play an important role. The most important determinants are for example according to Křivská (2009) profitability and stability of the firm, structure of assets of the firm, financial slack, the amount of investment, the firm's size, legislation, the amount of investment, and the branch of business. The last determinant would play a very important role.

The usage of the different theories will very strongly depend on the ability to cope with the application problems which arise in case of their application. It is necessary to identify the cost of equity and the cost of debt for the different levels of indebtedness. And that is a very complicated process. The cost of equity and debt will grow, but the problem is how much moderately and how much strongly. This application problem very strongly limits the usage of this in other respects very good theory.

Compromising theory is limited by the problem of the identification of the cost of financial distress. Levy and Marshall (1999) offered the solution of this problem and they recommend measuring the cost of financial distress as the fictional insurance against the bankruptcy. But the problem is how to identify these insurance payments.

Brealey et al.'s (2014) theory about four dimensions of capital structure recommends some procedures for optimizing, but it is not possible to identify according to this theory some concrete recommended value of indebtedness. MM propositions I and II are overcome.

Besides theoretical solutions, there are also some results of practical researches in the Czech Republic. Horová and Hrdý (2007) or Hrdý et al. (2008) presented that 55.6\% firms pursue the active optimizing of their capital structure considering mainly the cost of capital. Only $20 \%$ of the enterprises pay attention to the long-term optimizing of the capital structure, where these firms are trying to minimize the debt and maximize internal financial sources which represent Pecking Order Theory. More than $20 \%$ of firms do not take into consideration the process of the optimizing of the capital structure (Horová \& Hrdý, 2007). Relatively interesting are some researches that analyse the influence of the concrete industry branch (Hrdý, 2016; Hrdý, 2017). Talberg, Winge, Frydenberg, and Westgaard (2008) demonstrated significant difference in the capital structure depending on the industry. According to their study, debt ratio reports negative relation to profitability, growth, and age, on contrary of asset structure and company size with positive relation. Ghost and Cai (2011) examined whether enterprises converge their capital structure toward their industry mean. The empirical result found out that optimal capital structure is not a single point rather a range of values from zero to the industry and typical U.S. enterprises will only adjust to the optimal capital structure when the enterprises' debt level is out of this range. An extensive questionnaire for central and European countries was contented in study of Hernádi and Ormos (2013), who find that CFOs present rather strong Pecking Order Behaviour, with a limited role for target leverage. However, according to results, Trade-off Theory and Pecking Order Theory are not mutually exclusive. Ultimately, there is set of studies which devoted its attention to capital structures among Asian industrial enterprises: Iranian (Abzari, Fathi, \& Torosian, 2012), Indonesian (Hardiyanto, Achsani, \& 
Sembel, 2014), or Pakistan (Afza \& Hussain, 2011), not bringing such similar results. Present research in this field for Czech enterprises is not performed systematically, but it focuses only on particular aspects (Růčková \& Heryán, 2013; Hrdý \& Marek, 2012)

The theoretical and practical knowledge shows that the process of optimizing of the capital structure of the concrete firm is very complicated and that it is not easy to identify some optimal indebtedness. For that reason, the importance of the alternative steps is increasing. Optimizing of the capital structure according to the so-called branch standards can be one possibility how to cope with this very complicated situation. But there is the key question if it is possible to identify the average indebtedness and the so-called branch standards for different sectors in different countries.

It is possible to identify the basic hypothesis $\mathrm{H}_{0}$ that "It is possible to identify the average indebtedness and the so-called branch standards, but only in selected branches in selected countries". Besides this basic hypothesis can be identified, the alternative hypothesis $\mathrm{H}_{1}$ that "It is not possible to identify the average indebtedness and the so-called branch standards in practically none branch in selected countries". The $\mathrm{H}_{0}$ was confirmed and $\mathrm{H}_{1}$ was refused in the previous article of the author (Hrdý, 2018), so the question is if the same conclusion will be according to the researches in the next branches analysed in this article.

\section{Methods and Results}

This part describes data sources, methods used, and the results of the research that would be the same as in the previous article (Hrdý, 2018). Data for this research were used from the two key sources. The first source is represented by data obtained from the database Albertina in the University of Economics in Prague for the period 2008-2016. In this database, the information about firms in different branches in the Czech Republic including accounting data is available. This data were adjusted by elimination of the indebtedness over $100 \%$ and of the negative indebtedness. The only problem of the sources of information is the reality that not all the firms fulfil their obligation to publish the financial statement. It is supposed that data are relatively very credible with its information value. All data from the concrete branch are covered including the changes about the constitution or winding up of different firms. The number of firms is changing, but in the last three or two years, this number is relatively stabilized, and for that reason, this research is relatively credible. The objects of the research were the branches of Pharmacy, Furniture Production, Water Supply, Wood (Forest) Products, and Air Transport. The indebtedness in the Czech Republic was identified from accounting data because the market values were not available. For that reason, data from the USA were also identified from accounting data whereas the market data were also available. The database of the web page of Professor Aswath Damodaran ${ }^{1}$ was used. At this web page, a lot of information not only about the American firms is available including the indebtedness from accounting and market data in different branches. Because of the possibility of the comparison the same branches were chosen.

The methods used for the realization of this aim of the research are the analysis, the comparison, and the final synthesis of the analyzed information. Because the series of data are not so long, some more sophisticated statistical methods are not necessary, and the simple observation and analysis would be sufficient. The key matter for the final finding out would be the statement if the indebtedness in the last few years is relatively stabilized and if it would be possible to identify some average indebtedness and so-called branch standards as it

${ }^{1}$ Retrieved January 31, 2018, from http:// pages.stern.nyu.edu/ adamodar. 
was also in the previous article (Hrdý, 2018).

The following results were identified in different branches in the Czech Republic and in the USA and they are stated in the following five tables with some concise comments.

Table 1

The Average Indebtedness (AI)-Branch Pharmacy

\begin{tabular}{|c|c|c|}
\hline Year & Czech Republic (\%) & USA $(\%)$ \\
\hline 2008 & 41.50 & 31.01 \\
\hline 2009 & 38.71 & 33.27 \\
\hline 2010 & 33.64 & 32.05 \\
\hline 2011 & 33.67 & 30.99 \\
\hline 2012 & $36 ., 91$ & 32.79 \\
\hline 2013 & 35.75 & 33.54 \\
\hline 2014 & 36.25 & 34.18 \\
\hline 2015 & 35.75 & 33.70 \\
\hline
\end{tabular}

The Table 1 shows a relatively very stabilized position in the Czech Republic as well as in the USA. So, the situation is relatively easy and without problem and it is possible to identify the average indebtedness in both countries. The average indebtedness would be for the Czech Republic 35\% and for the USA 34\%. This average indebtedness can be for both countries identified as so-called branch standards. Both values are almost similar that confirms the relatively similar situation in the Pharmacy industry in both countries.

Table 2

The Average Indebtedness (AI)—Furniture Production

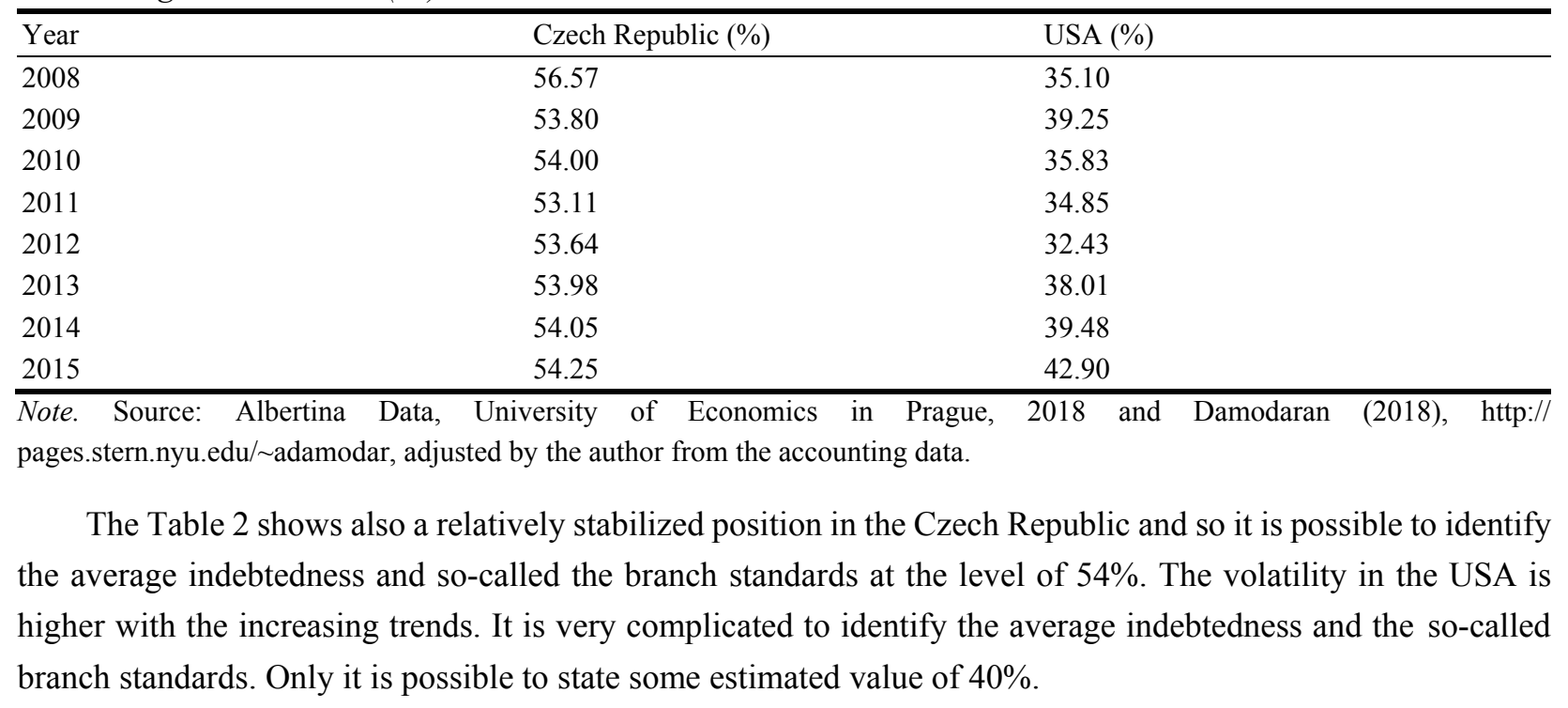


Table 3

The Average Indebtedness (AI)-Water Supply

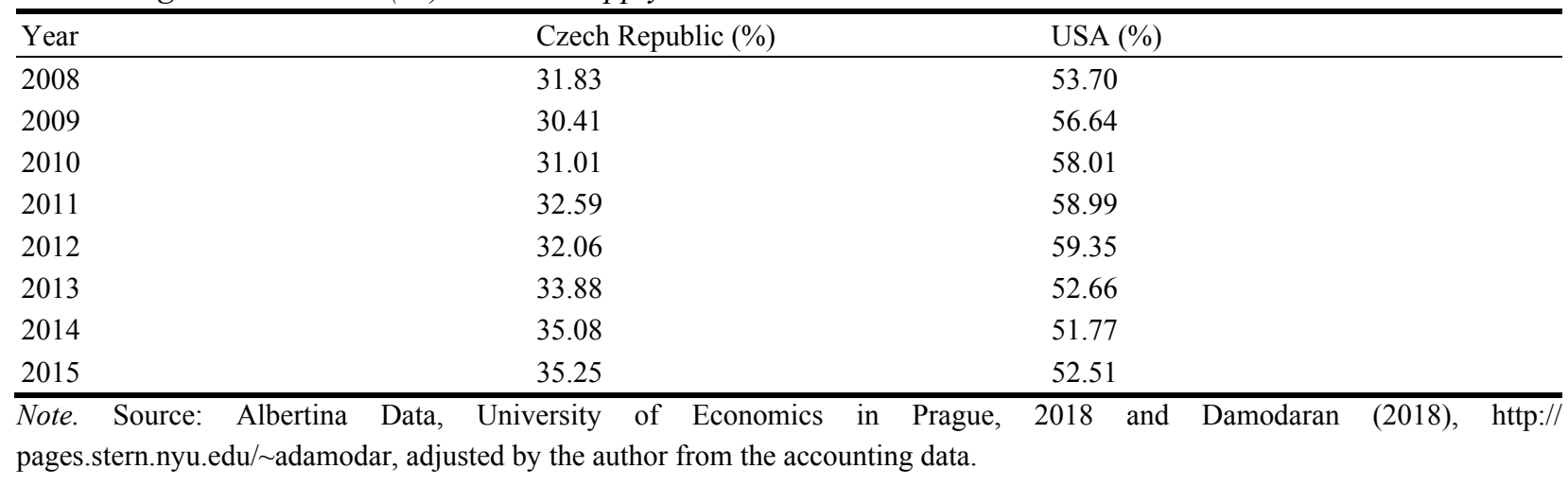

The Table 3 shows a slow increase of the indebtedness in the Czech Republic in the first year, but now the position is relatively stabilized about the value of $35 \%$ that can be used as the average indebtedness and the branch standards. The situation in the USA is more complicated, because after the initial decrease, the average indebtedness is then increasing, and it reaches approximately the same value as at the beginning. It is very difficult to identify the average indebtedness and the branch standards, but taking into account the last three years, the estimation of the average indebtedness and so-called branch standards could be identified on the level of $30 \%-35 \%$ in the Czech Republic and on the level of 55\%-50 \% in the USA.

Table 4

The Average Indebtedness (AI)-Wood (Forest) Products

\begin{tabular}{|c|c|c|}
\hline Year & Czech Republic (\%) & USA (\%) \\
\hline 2008 & 42.46 & 54.15 \\
\hline 2009 & 43.03 & 46.37 \\
\hline 2010 & 41.19 & 40.76 \\
\hline 2011 & 48.61 & 37.45 \\
\hline 2012 & 30.38 & 45.25 \\
\hline 2013 & 39.10 & 59.18 \\
\hline 2014 & 39.18 & 60.16 \\
\hline 2015 & 40.05 & 73.82 \\
\hline
\end{tabular}
pages.stern.nyu.edu/ adamodar, adjusted by the author from the accounting data.

The Table 4 shows after the initial volatility and changes of the indebtedness a relatively stabilized position in the Czech Republic and it is possible to identify the average indebtedness and so-called branch standards on the position of $40 \%$. The development in the USA is gain very volatile and it is not possible to identify the average indebtedness and the so-called branch standards. 
Table 5

The Average Indebtedness (AI)_Air Transport

\begin{tabular}{|c|c|c|}
\hline Year & Czech Republic (\%) & USA (\%) \\
\hline 2008 & 74.88 & 54.36 \\
\hline 2009 & 60.65 & 72.93 \\
\hline 2010 & 63.64 & 71.59 \\
\hline 2011 & 65.08 & 66.71 \\
\hline 2012 & 71.22 & 68.51 \\
\hline 2013 & 77.34 & 83.03 \\
\hline 2014 & 75.25 & 57.18 \\
\hline 2015 & 73.27 & 56.86 \\
\hline
\end{tabular}

The Table 5 shows a relatively high volatility in the Czech Republic and in the USA, even though the relatively stabilized position is identified in the last three years in the Czech Republic and it is possible to identify some estimation of the average indebtedness on the level of $70 \%-75 \%$. The situation in the USA is more complicated and it is not possible to identify the average indebtedness and so-called branch standards.

The branch standards were identified for the branch Pharmacy, Furniture Production, Water Supply, and Wood (Forest) Products in the Czech Republic and for the branch Pharmacy in the USA. The estimation of the average indebtedness and branch standards was identified for the branch Air Transport in the Czech Republic, and for the branch Furniture Production and Water Supply in the USA. The branch standards are not possible to identify for the branches Air Transport and Wood (Forest) Products in the USA. Now, it is necessary to verify this information by their confrontation with data in the year 2016. The situation is described in the Table 6 .

Table 6

Verification of Branch Standards

\begin{tabular}{lllll}
\hline Branch & $\begin{array}{l}\text { Branch standard } \\
\text { Czech Republic (\%) }\end{array}$ & $\begin{array}{l}\text { The indebtedness 2016 } \\
\text { Czech Republic (\%) }\end{array}$ & $\begin{array}{l}\text { Branch standard } \\
\text { USA (\%) }\end{array}$ & $\begin{array}{l}\text { The indebtedness 2016 } \\
\text { USA (\%) }\end{array}$ \\
\hline Pharmacy & 35.25 & 34 & 36.74 \\
Furniture Production & 54 & 54.15 & 40 & 41.98 \\
Water Supply & $30-35$ & 35.75 & $50-55$ & 53.71 \\
Wood (Forest) Products & 40 & 39.95 & - & 43.37 \\
Air Transport & 68.75 & - & 55.52 \\
\hline Note. Source: Albertina Data, University of Economics in Prague, 2018 and Damodaran (2018), http://
\end{tabular}

The result of Table 6 can be explained as follows. All so-called branch standards were confirmed excluding the branch Air Transport in the Czech Republic and for the branch Water Supply in the USA. But only relatively small deviations were identified for the branches Furniture Production and Pharmacy, so also here the branch standards could be confirmed. The problem was only in the branch Air Transport in the Czech Republic which confirms the fact that this branch is relatively volatile.

It could be relatively interesting to analyze the development in the branches in the USA where so-called branch standards were not identified. The branch Wood (Forest) Products shows a great volatility and so it can be confirmed the inability to identify the average indebtedness and so-called branch standards. The branch Air 
Transport shows a bit different situation, because some small decreasing tendency can be identified.

\section{Discussions and Conclusions}

This paper examines if it is possible to identify the average indebtedness and so-called branch standards. The hypothesis $\mathrm{H}_{0}$ was confirmed and the hypothesis $\mathrm{H}_{1}$ was rejected as it was also in the previous article (Hrdý, 2018). The key conclusion of this research consists in the fact that it is possible to identify the average indebtedness and so-called branch standards, but only in the selected branches where the tendency of the average indebtedness is relatively stabilized and where there is a minimum volatility in the last few years. So, the conclusions of the previous researches (Hrdý, 2018) were confirmed. There are relatively great differences among different branches and among countries. This conclusion confirms the findings from the previous researches (Hrdý, 2018) including the fact that the stability in the Czech Republic is in more branches than it is in the USA. It is very complicated to identify the reasons for this behavior because it depends on the different factors. The most important factors can be for example the situation on the capital markets, the changes in the economy, the position, and the development of the most important and strongest firms in the concrete branch, and the economic cycle in the selected branches. The discussion can also develop about the fact if the average indebtedness in some concrete branch is the optimum the theory is looking into. The answer to this question is not easy. But the average indebtedness would reflect the real risk in some concrete branch and some other conditions and for that reason the average indebtedness can be the result of the balance with the specifics of this concrete branch. For that reason, so-called branch standards have their relatively strong position in the theory and practice of the process of optimizing of the capital structure of the concrete firm.

There is a relatively great opportunity for the next research. Primarily, it is necessary to develop this research and the research of Hrdý (2018) when the next data in the following years would be available. Then, it would be possible to confirm the tendency for the stabilized position in the selected branches or vice versa identify the new wave of some volatility. Of course, this research has its limitations that are done by the fact that not all firms have actual information in databases.

\section{References}

Abzari, M., Fathi, S., \& Torosian, A. (2012). Inter-industry differences in capital structure and product market competition: Evidence from Iranian companies. Interdisciplinary Journal of Contemporary Research in Business, 3(9), 395-402.

Afza, T., \& Hussain, A. (2011). Determinants of capital structure across selected manufacturing sectors of Pakistan. International Journal of Humanities and Social Science, 1(12), 254-262.

Brealey, R., Myers, S. C., \& Allen, F. (2014). Theory and practice of corporate finance. Brno: Bizbooks.

Ghost, A., \& Cai, F. (2011). Optimal capital structure vs. pecking order theory: A further test. Journal of Business \& Economic Research, 2(8), 61-68.

Hardiyanto, A. T., Achsani, N. A., \& Sembel, R. (2014). The difference of capital structure among industry sectors in the Indonesia Stock Exchange. Business and Management Review, 3(8), 28-35.

Hernádi, P., \& Ormos, M. (2013). What managers think of capital structure and how they act: Evidence from Central and Eastern Europe. Baltic Journal of Economics, 12(2), 47-71.

Horová, M., \& Hrdý, M. (2007). Topical problems of strategic financial management of entreprises in the Czech Republic. $E \& M$ Ekonomie a Management, 10(4), 80-86.

Hrdý, M. (2016). Branch standards in the process of optimizing of capital structure. In 3rd International Multidisciplinary Scientific Conference on Social Sciences and Arts (SGEM 2016) (pp. 73-80). Sofia: SGEM. ISBN 978-619-7105-74-2

Hrdý, M. (2017). The analysis of indebtedness of firms in the Czech Republic, in the Europe and in the USA in selected branches. In Finance, Economics \& Tourism-4th International Multidisciplinary Scientific Conference on Social Sciences and Arts (pp. 571-578). Bulgaria: SGEM. ISBN 978-619-7408-15-7 
Hrdý, M. (2018). Branch standards as the possible way of optimizing of capital structure of the concrete firm. Journal of Modern Accounting and Auditing, 14(4), 165-173. doi:10.17265/1548-6583/2018.04.002

Hrdý, M., \& Marek, P. (2012). Optimizing of the capital structure of the concrete firm in the theory and practice of the temporary corporate finance. In Conference Proceedings of the 4th WSEAS World Multiconference on Applied Business and Development (AEBD 12) (pp. 77-82). Porto-Portugal: WSEAS Press.

Hrdý, M., Fetisovová, E., Horová, M., Hofman, J., Ježek, J., Ježková, R., ... Šimek, B. (2008). The comprehensive solution of theoretical and practical problems of financing of small and medium entreprises in the European Union. Plzeň: University of West Bohemia.

Křivská, R. (2009). Determinants of the capital structure and its optimizing (Doctoral dissertation, University of Economics in Prague, Prague).

Levy, H., \& Marshall, S. (2009). Capital investments and financial decisions. Prague: Grada.

Modigliani, F., \& Miller, M. H. (1958). The cost of capital, corporation finance and the theory of investment. The American Economic Review, 48(3), 261-297.

Růčková, P., \& Heryán, T. (2013). The capital structure management in companies from the building area in conditions of the Czech Republic. In S. Polouček and D. Stavárek (Eds.), Financials regulation and supervision in the after-crisis period (pp. 384-393). Karviná: Silesian University.

Talberg, M., Winge, C., Frydenberg, S., \& Westgaard, S. (2008). Capital structure across industries. International Journal of the Economics of Business, 15(2), 181-200.

Valach, J. (2011). Investments decision and long-term financing (3rd ed.). Prague: Ekopress, Ltd. ISBN 978-80-86929-71-2 